\title{
Estimating Lookback Price Using Monte Carlo Simulation and Binomial Lattice
}

\author{
Fauziah Sudding ${ }^{1, *}$ Yusuf Kalla ${ }^{2}$ \\ ${ }^{1}$ Actuarial Science Department, President University, Ki Hajar Dewantara Street, North Cikarang, Bekasi, Indonesia \\ ${ }^{2}$ PT Reasuransi Indonesia Utama, Jakarta, Indonesia \\ *Email: fauziahfahirah@president.ac.id
}

\begin{abstract}
Lookback options are path-dependent option, whose payoffs depend on the maximum and minimum value of the underlying assets throughout the duration of the contract. Since the payoffs are calculated based on the asset price during the lifetime of the option, there are no analytic formulas yet to evaluate the price of the option. However, the approximation can be obtained using numerial methods. Monte carlo simulation and binomial lattice are two of those numerical methods that will be applied in this paper. Numerical solution using monte carlo is obtained by generating the future price of assets that will be later used in estimating the option and binomial model also does similar action, the only different is all possible paths of the underlying asset are based on the assumption that the stock price for next period will move into two possible values, either up or down. The price lookback option have been computed both for fixed strike lookback call and put; and floating strike lookback call and put, the approximation using the both numerical analysis are compared with analytic Black-School results, and shown that Binomial lattice gives better numerical solution than Monte Carlo. However, the values in Binomial are not entirely close to Black-Scholes, it shows poor performance in Floating Strike Lookback Put Option. Monte Carlo, on the other hand, does not work very well for pricing this option.
\end{abstract}

Keywords: Binomial Lattice, Lookback Option, Monte Carlo Simulation, Option.

\section{THEORY AND MODEL DESIGNED}

Lookback options are path-dependent option, whose payoffs depend on the maximum and minimum value of the underlying assets throughout the duration of the contract. At maturity, the holder has right to buy the assets at lowest price (call option) or sell the underlying asset at highest price (put option). This option is known to be more expensive compared to vanilla option with similar payoff function, because it gives the buyer an advantage to "look back" the price of underlying asset during the life of the option to determine the payoff.

Since, the payoff of this option is calculated based on asset price during the contract, there are no analytic formulas yet to determine the price. And the main objective to carry out this research is to approximate the price using two different types of numerical method, they are monte carlo simulation and binomial lattice.

\subsection{Lookback Option}

Lookback option is one of an exotic option with path dependency. It is classified into two types, they are fixed strike lookback and floating strike lookback. The payoffs are stated, as follows:

a. Fixed strike lookback

The call payoff is determined by finding the difference between maximum price and strike price, if positive.

$\mathbf{V}_{\mathbf{c}}(\mathbf{T})=\left(\mathbf{S}_{\max }-\mathbf{K}\right)^{+}$

And calculating the difference between strike price and minimum price over the life of the option for put option, if positive.

$\mathbf{V}_{\mathbf{p}}(\mathbf{T})=\left(\mathbf{K}-\mathbf{S}_{\mathbf{m i n}}\right)^{+}$ 


\section{b. Floating strike lookback}

The payoffs for floating strike lookback depend not only on maximum and minimum value of asset price over the monitoring period but also the asset price at maturity. That are,

$\mathbf{V}_{\mathbf{c}}(\mathbf{T})=\left(\mathbf{S}_{\mathbf{T}}-\mathbf{S}_{\min }\right)^{+}$

for call. And,

$\mathbf{V}_{\mathbf{p}}(\mathbf{T})=\left(\mathbf{S}_{\max }-\mathbf{S}_{\mathbf{T}}\right)^{+}$

for put.

\subsection{Monte Carlo Simulation}

Monte carlo simulation is used on valuating the price of the option when there is no known analytical formula for it. It was first introduced by John Von Neumann and Stanislaw Ulam. This simulation gives numerical solution by generating the future price of assets. The most widely used model of stock price behavior is

$\mathbf{S}_{\boldsymbol{T}}^{\mathbf{j}}=\mathbf{S}_{\boldsymbol{t}} \exp \left[\left(\mu-\frac{1}{2} \sigma^{2}\right) \mathrm{T}+\sigma \mathrm{z} \sqrt{\Delta \mathrm{t}}\right]$

Where $j=1,2, \ldots, M$ and $M$ refers to the number of trials or possible future value of assets at maturity. And the $z$ denotes the random variable generated from standard normal distribution. The variable $\sigma$ is volatility of stock price and variable $\mu$ is its expected rate of return.

After projecting the future assets, now we can calculate the payoffs. The expected value of payoffs will be discounted. Repeat the procedure for high number of simulated sample path. The average of those results obtained is the option value.

There are two different models that will be used in simulating the option, standard monte carlo and variance reduction technique.

\subsubsection{Standard Monte Carlo}

Let consider a general random variable $X$, with mean $\mathrm{E}[X]=a$ and variance $\operatorname{Var}[X]=b^{2}$ are unknown. The approximation of the mean can be calculated by computing the average of a large number of samples. Now let $X_{1}, X_{2}, \ldots, X_{M}$ denote the independent random variables with similar distribution as $X$, hence,

$\mathrm{a}_{M}=\frac{1}{\mathrm{M}} \sum_{\mathrm{i}=1}^{\mathrm{M}} \mathrm{X}_{i}$

and,

$\mathrm{b}_{M}^{2}=\frac{1}{\mathrm{M}-1} \sum_{\mathrm{i}=1}^{\mathrm{M}}\left(\mathrm{X}_{i}-\mathrm{a}_{M}\right)^{2}$

are unbiased estimators of $a$ and $b$, respectively.

By the central limit theorem, $\sum_{i=1}^{M} X_{i}$ behaves like $N \sim\left(M a, M b^{2}\right)$ random variables. Then,

$\mathrm{a}_{M}-\mathrm{a} \sim \mathrm{N}\left(0, \frac{\mathrm{b}^{2}}{\mathrm{M}}\right)$ or,

$\frac{\mathrm{a}_{M}-\mathrm{a}}{\frac{\mathrm{b}}{\sqrt{\mathrm{M}}}} \sim \mathrm{N}(0.1)$

Hence, the expected value of $a$ lies in the interval,

$\left[\mathrm{a}_{M}-\frac{1.96 \mathrm{~b}_{M}}{\sqrt{\mathrm{M}}}, \mathrm{a}_{M}+\frac{1.96 \mathrm{~b}_{M}}{\sqrt{\mathrm{M}}}\right]$

with probability $95 \%$, approximately. This analysis is the standard monte carlo for approximating $a$. There are two importants points to note : (1)To reduce the error, it requires a increase number of simulation $M$.(2) To produce more accurate estimator, we may transform the problem of estimating $\mathrm{E}[X]$ to the problem of estimating $\mathrm{E}[Y]$, where $Y$ is another random variable that has similar mean with $X$ but a smaller variance, and this method is known as variance reduction

\subsubsection{Variance Reduction Technique}

Suppose that we want to estimate $\mathrm{E}[X]$, using another random variable $Y$ whose the mean $E[Y]$ has approximately same value as $\mathrm{E}[X]$. Then random variable,

$\mathrm{Z}=\mathrm{X}+\mathrm{E}[\mathrm{Y}]-\mathrm{Y}$

Satisfies $\mathrm{E}[\mathrm{Z}]=\mathrm{E}[\mathrm{X}]+\mathrm{E}[\mathrm{Y}]-\mathrm{E}[\mathrm{Y}]=\mathrm{E}[\mathrm{X}]$, and hence the monte carlo simulation can be applied to $Z$ instead of $X$. In this context, the variable $Y$ is known as control variate.

Furthermore, since we want to have smaller variance than $X$, the $Z$ can be generalized to,

$\mathrm{Z}_{\theta}=\mathrm{X}+\theta(\mathrm{E}[\mathrm{Y}]-\mathrm{Y})$

for any $\theta \in \mathbb{R}$. Note that $\mathrm{E}\left[Z_{\theta}\right]=\mathrm{E}[X]$, hence monte carlo can still be applied to $Z_{\theta}$. And,

$\operatorname{Var}\left[\mathrm{Z}_{\theta}\right]=\operatorname{Var}[\mathrm{X}]-2 \theta \operatorname{Cov}(\mathrm{X}, \mathrm{Y})+\theta^{2} \operatorname{Var}[\mathrm{Y}]$

Since $\theta$ varies, the value of $\theta$ that minimizes this quadratic is given by

$\theta_{\min }:=\frac{\operatorname{Cov}[\mathrm{X}, \mathrm{Y}]}{\operatorname{Var}[\mathrm{Y}]}$

Furthermore, it shows that $\operatorname{Var}\left[Z_{\theta}\right]<\operatorname{Var}[X]$, if and only if $0<\theta<2 \theta_{\text {min }}$. The general concern is the unknown $\operatorname{Cov}[X, Y]$ hence cannot find $\theta_{\text {min }}$. However, it is still possible to approximate $\operatorname{Cov}[X, Y]$ during monte carlo simulation.

\subsection{Binomial Lattice}

Binomial lattice is a discrete method in valuating option price that gives different possible paths of the underlying asset might be followed during the contract. It is based on the assumption that the stock price for next period will move into two possible values, either up or down. 
All possible movements of asset price using binomial model are represented in the following binomial tree below:

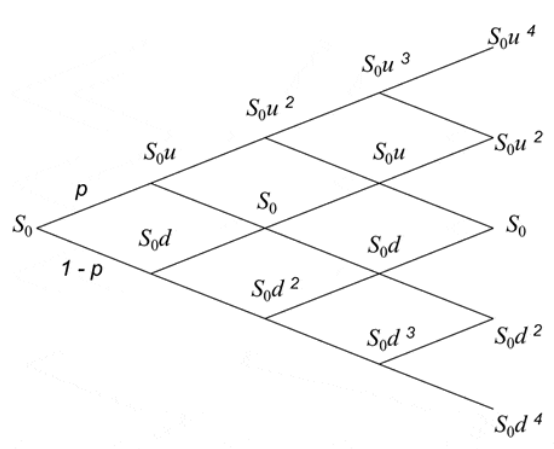

Figure 1 Binomial tree of asset price

The figure above shows that the current asset price, $S_{0}$ will either go up to $S_{0} u$ with probability $p$ or go down to $S_{0} d$ with probability $1-p$ in one time period, where $u$ dan $d$ are increase and decrease factors, respectively, and $d<1<u$.

All nodes of asset price in the future with this method is defined as :

$\mathrm{S}_{T}=\mathrm{S}_{0} \mathrm{u}^{\mathrm{j}} \mathrm{d}^{\mathrm{n}-\mathrm{j}}, \mathrm{j}=1,2, \ldots, \mathrm{n}$

Where $\mathrm{u}=\mathrm{e}^{\sigma \sqrt{\Delta \mathrm{t}}}$ and $\mathrm{d}=1 / \mathrm{u}=\mathrm{e}^{-\sigma \sqrt{\Delta \mathrm{t}}}$.

After projecting the asset price, option is now numerically able to calculated. It starts at the last period by finding all the payoffs then working back toward the first period, that is,

$\mathrm{V}_{i j}=\mathrm{e}^{-\mathrm{r} \Delta \mathrm{t}}\left[\mathrm{pV}_{i+1, j+1}+(1-\mathrm{p}) \mathrm{V}_{i+i, j}\right]$; $\mathrm{i}=\mathrm{n}, \mathrm{n}-1, \ldots, 1,0 ; \quad \mathrm{j}=\mathrm{n}, \mathrm{n}-1, \ldots, 1,0$

where,

$p=\frac{e^{r \Delta t}-d}{u-d}$

\section{RESULTS}

\subsection{Numerical Example and Results}

In order to estimate the price of the option, let set some values needed. Consider $S_{0}=50, r=6 \%, \sigma=$ $0.30, \mathrm{~T}=1, \mathrm{n}=50$. The results obtained are shown in Table 1, Table 2, Table 3, and Table 4 below.

\subsubsection{Fixed Strike Lookback Option Using Monte Carlo Simulation and Binomial Lattice.}

Table 1 and Table 2 show the results of the simulation for fixed strike lookback call and put option with given parameters, respectively. Monte Carlo gives less accurate estimation once $\mathrm{K}$ increases (greater or equal to stock price $S_{0}$ ) for lookback call. While in put option case, the option value is close to the value from Black Scholes only if strike price is equal to the current stock price. The standard deviations of this estimation have been decreased in variance reduction technique. However, the results still give significant difference from Black Scholes.

On the other hand, Binomial Lattice gives better performance than Monte Carlo. We can easily see that those approximations are much closer to Black-Scholes.

Table 1. Fixed Strike Lookback Call Option

\begin{tabular}{|r|r|r|r|r|r|r|r|}
\hline \multicolumn{1}{|c|}{$\boldsymbol{K}$} & \multicolumn{1}{|c|}{$\boldsymbol{B}-\mathbf{S}$} & Binomial & $\begin{array}{c}\text { Standard } \\
\text { Monte Carlo }\end{array}$ & $\begin{array}{c}\text { Variance } \\
\text { Reduction }\end{array}$ & $\begin{array}{c}\text { 95\% Confidence } \\
\text { Interval (Std. MC) }\end{array}$ & $\begin{array}{c}\text { 95\% Confidence } \\
\text { Interval (VR) }\end{array}$ \\
\hline 90 & 50 & 20.2509 & 24.0759 & 20.5793 & 20.5793 & {$[18.2478,22.9108]$} & {$[19.6127,21.5459]$} \\
\hline & 500 & & & 20.1844 & 20.1844 & {$[19.4088,20.9600]$} & {$[19.8355,20.5334]$} \\
\hline & 5000 & & & 20.4200 & 20.4200 & {$[20.1622,20.6777]$} & {$[20.3107,20.5293]$} \\
\hline 100 & 50 & 14.7171 & 14.7112 & 11.8147 & 11.8147 & {$[8.1391,15.4902]$} & {$[10.5781,13.0512]$} \\
\hline & 500 & & & 10.6117 & 10.6117 & {$[9.8288,11.3947]$} & {$[10.2718,10.9517]$} \\
\hline & 5000 & & & 10.5508 & 10.5508 & {$[10.2948,10.8069]$} & {$[10.4435,10.6582]$} \\
\hline 110 & 50 & 10.4241 & 10.4082 & 4.6502 & 4.6502 & {$[2.5353,6.7652]$} & {$[3.2698,6.0306]$} \\
\hline & 500 & & & 4.7509 & 4.7509 & {$[4.0306,5.4712]$} & {$[4.3481,5.1537]$} \\
\hline & 5000 & & & 3.8708 & 3.8708 & {$[3.6821,4.0594]$} & {$[3.7566,3.9850]$} \\
\hline
\end{tabular}


Table 2. Fixed Strike Lookback Put Option

\begin{tabular}{|r|r|r|r|r|r|r|r|}
\hline \multicolumn{1}{|c|}{$\boldsymbol{K}$} & \multicolumn{1}{|c|}{$\boldsymbol{m}$} & \multicolumn{1}{c|}{ B-S } & \multicolumn{1}{c|}{$\begin{array}{c}\text { Standard } \\
\text { Monte Carlo }\end{array}$} & $\begin{array}{c}\text { Variance } \\
\text { Reduction }\end{array}$ & $\begin{array}{c}\text { 95\% Confidence } \\
\text { Interval (Std. MC) }\end{array}$ & $\begin{array}{c}\text { 95\% Confidence } \\
\text { Interval (VR) }\end{array}$ \\
\hline 90 & 50 & 5.0097 & 5.0278 & 1.4758 & 1.4758 & {$[0.6063,2.3454]$} & {$[0.7844,2.1673]$} \\
\hline & 500 & & & 2.3603 & 2.3603 & {$[1.9731,2.7474]$} & {$[2.0960,2.6245]$} \\
\hline & 5000 & & & 2.4134 & 2.4134 & {$[2.9283,2.5341]$} & {$[2.3288,2.4980]$} \\
\hline 100 & 50 & 8.8935 & 8.8347 & 9.0859 & 9.0859 & {$[7.0112,11.1607]$} & {$[7.8187,10.3531]$} \\
\hline & 500 & & & 8.0473 & 8.0473 & {$[7.4707,8.6238]$} & {$[7.7838,8.3107]$} \\
\hline & 5000 & & & 8.6395 & 8.6395 & {$[8.4484,8.8305]$} & {$[8.5486,8.7303]$} \\
\hline 110 & 50 & 14.0182 & 18.2524 & 17.1138 & 17.1138 & {$[15.3270,18.9006]$} & {$[16.1867,18.0409]$} \\
\hline & 500 & & & 18.1211 & 18.1211 & {$[17.5232,18.7189]$} & {$[17.8117,18.4304]$} \\
\hline & 5000 & & & 18.6866 & 18.6866 & {$[18.4921,18.8810]$} & {$[18.5964,18.7767]$} \\
\hline
\end{tabular}

\subsubsection{Floating Strike Lookback Option.}

Table 3 and Table 4 show the projection of Floating Strike Lookback Call and Put Option using Monte Carlo and Binomial Lattice. Binomial lattice give another great

Table 3. Floating Strike Lookback Call Option performance in valuing the lookback call option. However, it is not the case for put option. Moreover, poor performance is also given by Monte Carlo, both for standard monte carlo and variance reduction technique. The values from Black Scholes are not even on the interval given from both simulations.

\begin{tabular}{|c|c|c|r|r|r|r|r|}
\hline $\boldsymbol{K}$ & $\boldsymbol{m}$ & $\mathbf{B}-\mathbf{S}$ & Binomial & $\begin{array}{c}\text { Standard } \\
\text { Monte Carlo }\end{array}$ & $\begin{array}{c}\text { Variance } \\
\text { Reduction }\end{array}$ & $\begin{array}{c}\text { 95\% Confidence } \\
\text { Interval (Std. MC) }\end{array}$ & $\begin{array}{c}\text { 95\% Confidence } \\
\text { Interval (VR) }\end{array}$ \\
\hline 90 & 50 & 15.4037 & 14.6583 & 9.8463 & 9.8463 & {$[7.7502,11.9406]$} & {$[8.1219,11.5708]$} \\
\hline & 500 & & & 9.7962 & 9.7962 & {$[9.0169,10.5756]$} & {$[9.1745,10.4180]$} \\
\hline & 5000 & & & 9.9381 & 9.9381 & {$[9.6886,10.1876]$} & {$[9.7442,10.1320]$} \\
\hline 100 & 50 & & 14.7112 & 11.3735 & 11.3735 & {$[7.9163,14.8307]$} & {$[9.3592,13.3879]$} \\
\hline & 500 & & & 9.6889 & 9.6889 & {$[8.9170,10.4609]$} & {$[9.0706,10.3073]$} \\
\hline & 5000 & & & 9.6944 & 9.6944 & {$[9.4449,9.9438]$} & {$[9 . .4992,9.8895]$} \\
\hline 110 & 50 & & 14.6583 & 11.1680 & 11.1680 & {$[8.4362,13.8998]$} & {$[9.1129,13.2231]$} \\
\hline & 500 & & & 10.98840 & 10.98840 & {$[10.0991,11.8777]$} & {$[10.3420,11.6348]$} \\
\hline & 5000 & & & 9.74316 & 9.74316 & {$[9.4975,9.9888]$} & {$[9.55148,9.9349]$} \\
\hline
\end{tabular}

Table 4. Floating Strike Lookback Put Option

\begin{tabular}{|r|r|r|r|r|r|r|r|}
\hline \multicolumn{1}{|c|}{$\boldsymbol{K}$} & $\boldsymbol{m}$ & $\mathbf{B}-\mathbf{S}$ & Binomial & $\begin{array}{c}\text { Standard } \\
\text { Monte Carlo }\end{array}$ & $\begin{array}{c}\text { Variance } \\
\text { Reduction }\end{array}$ & $\begin{array}{c}\text { 95\% Confidence } \\
\text { Interval (Std. MC) }\end{array}$ & $\begin{array}{c}\text { 95\% Confidence } \\
\text { Interval (VR) }\end{array}$ \\
\hline 90 & 50 & 14.29057 & 8.83472 & 8.79498 & 8.79498 & {$[7.05742,10.53253]$} & {$[7.09837,10.49158]$} \\
\hline & 500 & & & 9.28526 & 9.28526 & {$[8.61593,9.95459]$} & {$[8.69807,9.87244]$} \\
\hline & 5000 & & & 9.39727 & 9.39727 & {$[9.18934,9.60519]$} & {$[9.21212,9.58242]$} \\
\hline 100 & 50 & & 8.88763 & 9.52705 & 9.52705 & {$[7.55245,11.50165]$} & {$[7.81928,11.23482]$} \\
\hline & 500 & & & 8.97066 & 8.97066 & {$[8.35629,9.58385]$} & {$[8.41873,9.52141]$} \\
\hline & 5000 & & & 9.49590 & 9.49590 & {$[9.29388,9.69791]$} & {$[9.31556,9.67624]$} \\
\hline 110 & 50 & & 8.83472 & 7.43422 & 7.43422 & {$[5.63658,9.23186]$} & {$[5.86098,9.00745]$} \\
\hline & 500 & & & 8.744033 & 8.744033 & {$[8.10166,9.38641]$} & {$[8.16052,9.32754]$} \\
\hline & 5000 & & & 9.540230 & 9.540230 & {$[9.33581,9.74468]$} & {$[9.35860,9.72186]$} \\
\hline
\end{tabular}

\section{CONCLUSION}

In this paper, Monte Carlo Method and Binomial Lattice have been applied to approximate the price of lookback option. According to the results, the Binomial lattice gives better numerical solution than Monte Carlo. However, the values in Binomial are not entirely close to Black-Scholes, it shows poor performance in Floating Strike Lookback Put Option for all possible values of strike price. in addition, the result in Fixed Strike Lookback Put also show significant difference as $K$ increases. Monte Carlo, on the other hand, does not work very well for pricing this option. Moreover, the values from Black Scholes are not even within the interval that are provided by both Standard Monte Carlo and Variance Reduction Technique.

\section{REFERENCES}

[1] D.J. Higham, An Introduction to Financial Option Valuation, Cambridge: Cambridge University Press, 2004 
[2] J.C. Hull, Option, Future, and Other Derivatives, Canada: Pearson Education International, 2018

[3] S.G. Kellison, The Theory of Interest 3rd Edition, McGraw-Hill International Edition, 2009

[4] S.M. Ross, An Elementary Introduction to Mathematical Finance 3rd Edition, Cambridge: Cambridge University Press, 2011
[5] H.U. Gerber, E.S.W. Shiu, Pricing Lookback Options and Dynamic Guarantees, in: North American Actuarial Journal vol 3 issue 4 (The Society of Actuaries), 2003, pp. 94-95. DOI: https://doi.org/10.1080/10920277.2003.10596076

[6] G.M. Jabbour, Y.K. Liu, Option Pricing and Monte Carlo Simulations, in: Journal of Business \& Economics Research vol 3 no 9, 2005. DOI: https://doi.org/10.19030/jber.v3i9.2802 